\title{
Factors associated with mortality among patients with culture-positive pulmonary tuberculosis in the urban poor population of Osaka City, Japan
}

\author{
Akira Shimouchi, a,b Yuko Tsuda, ${ }^{c}$ Jun Komukai, ${ }^{c}$ Kenji Matsumoto, ${ }^{d}$ Hideki Yoshida ${ }^{c}$ and Akihiro Ohkado ${ }^{b}$ \\ Correspondence to Akira Shimouchi (email: ak-shimouchi@city.osaka.lg.jp)
}

Objective: To determine the characteristics associated with mortality in patients with culture-positive pulmonary tuberculosis (PTB) in Airin, Osaka City, Japan.

Methods: The characteristics of patients with culture-positive PTB registered between 2015 and 2018 in Airin, Osaka City, Japan, were compared between those who died of all causes before or during treatment and those who completed treatment.

Results: Of the 241 culture-positive PTB patients eligible for this study, 170 completed treatment, with negative sputum culture tests, and 62 died. The all-cause case fatality rate was 26.7\% (62/232). Multivariate analysis showed that mortality was associated with age $\geq 70$ years, having a positive sputum smear, a body mass index of $<18.5$ and serious comorbidities such as cancer and heart and renal disease. Detection of tuberculosis (TB) by screening or in an outpatient department (OPD) for other diseases was inversely associated with mortality.

Discussion: Detection of PTB by chest X-ray screening and during regular visits to OPDs for other diseases was associated with non-fatal TB and might contribute to early case finding. Therefore, current active TB case finding and health education on regular visits to physicians for other diseases should be strengthened further for the urban poor population of Osaka City, Japan.

A key milestone of the World Health Organization's End TB Strategy is a $75 \%$ reduction in deaths from tuberculosis (TB) between 2015 and 2025 worldwide. ${ }^{1}$ To achieve this, the annual decrease in the estimated global incidence rate of TB (110 per 100000 population in 2015) should be accelerated from $2 \% /$ year in 2015 to $10 \% /$ year in 2025 , and the case fatality rate among TB patients should be reduced from 15\% in 2015 to $6.5 \%$ in $2025 .{ }^{1}$

In Japan in 2018, the TB incidence rate was 12.3 per 100000 , corresponding to an annual reduction of $6 \%$ from 2013. The TB case fatality rate in 2017 was $22.5 \%$ in all age groups but was higher for patients aged $\geq 70$ years $\left(34.6 \%\right.$ vs $4.9 \%$ for patients aged $0-69$ years). ${ }^{3}$ Neither indicator meets the global targets.
In 2018, Osaka City had the highest TB notification rate of all cities in Japan, at 29.3 per 100000 population, and the highest rate (298 per 100000 ) was in the small, densely populated area of Airin $\left(21500 / 0.62 \mathrm{~km}^{2}\right){ }^{2}$ The annual reduction in the TB incidence rate in Airin during 2013-2018 was 5\%, ${ }^{2}$ similar to the national average. The TB case fatality rate in Airin during 2015-2018 was $25.9 \%$ for all age groups, $15.5 \%$ for patients aged 0-69 years and $41.7 \%$ for patients aged $\geq 70$ years. $^{2}$

Airin was a residential area during the country's period of economic growth between the 1950s and the 1980s, accommodating Japan's largest population of day labourers, including factory, dock and construction workers. Its peak population was in 1960, when there were 30306 residents. ${ }^{4}$ During the economic recession

Nishinari District Public Health Office, Osaka City, Japan

The Research Institute of Tuberculosis, Japan Anti-Tuberculosis Association, Japan.

Osaka City Public Health Office, Japan.

Faculty of Health and Nutrition, Otemae University, Japan.

Published: 16 September 2021

doi: 10.5365/wpsar.2021.12.3.836 
in 1993, however, many lost their jobs, some became homeless and the influx of workers into Airin ceased. The number of day labourers covered by insurance fell by $91.7 \%$, from 24458 in 1986 to 2025 in $2009 .{ }^{4}$ As a result, the population has aged, the percentage of the population aged $\geq 65$ years increasing from 8 to $10 \%$ in $1975-1990$ to $20 \%$ in $2000,30 \%$ in $2005,40 \%$ in $2010^{4}$ and $45 \%$ in $2015 .^{2}$ Airin has the highest proportion of population aged $\geq 65$ years in Osaka City, where the city average was $25 \%$ in $2015 .^{5}$

In 2015, the population of Airin was 21 500; 81\% were male, $52 \%$ were pensioners or day labourers, $43 \%$ were in a public assistance programme (PAP) that provides free medical services and $5 \%$ were homeless. In comparison, $6 \%$ of the population of Osaka City are in a PAP. More than half of all homeless people in Osaka City live in Airin. ${ }^{2,5}$ Consequently, the population of Airin has become the oldest and the poorest in Osaka City.

To reduce the high TB notification rate in Airin, the community TB control programme has strengthened active case finding through chest $X$-ray screening and directly observed treatment (DOT) since $2013 .{ }^{2}$ Active case finding comprises chest X-rays of all residents, including the homeless, at public health centres and in mobile units. Homeless people are encouraged to be screened at various facilities, such as shelters. Patients undergo chest X-ray screening during annual health checks and may also be screened in outpatient departments (OPDs) during visits for other diseases if the attending physician suspects TB or another respiratory disease. If any abnormal shadow is detected, further examinations are conducted, such as sputum smears for acid-fast bacilli, nucleic acid amplification, culture and computed tomography, mainly at Osaka Social Medical Center.

During 2015-2018, 92.1\% (290/315) of PTB patients in Airin received daily DOT, whereby patients take anti-TB medicines daily in front of health care staff for the duration of treatment, in hospitals or in the community. ${ }^{2}$

The patient characteristics reported to increase the rate of TB case fatality in industrialized countries include demographic factors (increased age, male sex), social factors (homelessness), clinical aspects (positive sputum smear, multidrug-resistant TB, undernutrition/underweight, inadequate treatment, HIV infection) ${ }^{6-12}$ and serious comorbidities such as those listed in the Charlson comorbidity index (17 conditions) or the Elixhauser score (30 comorbidities). ${ }^{13,14}$

The aim of this study was to guide interventions to reduce mortality from TB by determining the characteristics associated with mortality in patients with culture-positive PTB in Airin, Osaka City, between 2015 and 2018.

\section{METHODS}

\section{Study population}

TB is a notifiable disease under the Infectious Disease Control Law in Japan; thus, physicians must report all TB cases to their local government. PTB patients registered in Airin between January 2015 and December 2018 were included in the study if they were alive at diagnosis, examined by chest X-ray and were culture-positive. Culture-positive PTB was defined as the presence of Mycobacterium tuberculosis in cultured sputum identified by immune-chromatography or nucleic acid amplification. Notifications of extrapulmonary TB were excluded, as most were not bacteriologically proven. Eligible PTB patients with coexisting extrapulmonary TB such as lymphadenitis and pleuritis were included.

Patients who moved out of Osaka City during the treatment period, in whom treatment failed (i.e. culture reversed from negative to positive or was persistently positive during treatment) or who were lost to follow-up were excluded from the analysis.

\section{Data collection}

In routine practice, public health nurses (PHNs) at local public health centres record data on individual TB patients on structured patient cards, which are then entered onto an electronic spreadsheet. The data include sex, age, social condition (homeless or not), chest X-ray findings, bacteriological test results, mode of case detection and comorbidities. During interviews with the cases, PHNs also collect information such as height and body weight.

\section{Determination of death}

In Japan, a TB patient's attending physician is solely responsible for diagnosing the cause of death as TB-specific or non-TB-specific. In Osaka City, attending physicians 
and medical staff at the Public Health Office have monthly meetings at each hospital where TB patients are treated to discuss and agree on the cause of each TB patient's death (TB or non-TB) for official records. Furthermore, by police request, any death of unknown cause identified in Osaka City is investigated by the Osaka Coroner's Office, by inspection or autopsy.

\section{Variables}

The outcome variables for this study were (1) treatment success: treatment completed and culture negative, "cured" for smear-positive patients and "treatment completion" for smear-negative patients; and (2) death: patients who died of any cause before or during treatment.

Possible explanatory variables were: sex (male, female); age ( $<70, \geq 70$ years); homelessness (yes, no); cavity finding on chest X-ray (present, absent); bacteriological test results: sputum smear on Ziehl-Neelsen staining (positive, negative) and susceptibility to all five first-line anti-TB medicines, isoniazid, rifampicin, ethambutol, streptomycin and pyrazinamide (yes, no); body mass index (BMI) $\left(<18.5, \geq 18.5 \mathrm{~kg} / \mathrm{m}^{2}\right)$; detection by "active screening" (yes, no), diabetes mellitus (present, absent); and other serious comorbidities (yes, no).

"Detection by active screening" was defined as diagnosis from a chest X-ray during active screening or at an outpatient visit for other diseases. This was compared with all other detection categories, e.g. at an outpatient visit for TB symptoms or during hospitalization for other diseases.

As diabetes mellitus was not shown to be associated with TB disease in a previous case-control study in Airin in $2015-2018,{ }^{15}$ this was analysed separately from other comorbidities.

\section{Analysis}

To ascertain associations between the explanatory variables and mortality, univariate analysis was conducted with the $\chi^{2}$ test. Three separate analyses were conducted against treatment success: all deaths, early deaths (de- fined as death before or within the first 2 months of TB treatment) and late deaths (defined as death during the third month of treatment or later). The characteristics of TB-specific and non-TB-specific deaths were also compared. Variables with $P<0.1$ were included in binomial multivariate logistic regression analysis, and adjusted odds ratios (aOR) were calculated.

Backward stepwise selection was applied to the binomial multivariate analysis. $P<0.05$ was considered statistically significant. The univariate analysis was performed in Microsoft Excel $\circledast 2$ 2016, and binomial multivariate analysis was performed with SPSS version 11.0J for Windows (SPSS Inc., Chicago, IL, USA).

\section{Ethical considerations}

The Ethical Review Committee of the Research Institute of Tuberculosis, Japan Anti-Tuberculosis Association, Tokyo, Japan, approved the study protocol (authorization number: RIT/IRB 2019-20). Informed consent was not obtained from eligible TB patients, as it is not required by the research ethics guidelines of the Japanese Government when research is conducted retrospectively from de-individualized, anonymous data collected routinely by legal requirement.

\section{RESULTS}

Between January 2015 and December 2018, 342 TB patients were registered in Airin. One was diagnosed with TB at autopsy, two were clinically diagnosed and died before chest X-ray examination and 18 had extrapulmonary TB. Of the remaining 321 PTB patients who underwent a chest X-ray, 241 were culture-positive and 80 were culture-negative. Of the 241 culture-positive PTB cases, nine were transferred out of Osaka City, and none had treatment failure or was lost to follow-up. Therefore, 232 culture-positive PTB patients were included in the analysis (Fig. 1).

The mean age of the study participants was 66.4 years (range, 19-97), 95.7\% ( $n=222)$ were male, $51.9 \%(n=121)$ were enrolled in PAP, and $29.2 \%$ ( $n=68$ ) were homeless. There were two foreign-born patients. 
Table 1. Serious comorbidities included in the study of enrolled pulmonary tuberculosis patients, Airin, Osaka City, Japan, 2015-2018

\begin{tabular}{ll}
\hline \multicolumn{1}{c}{ Cancer } & \multicolumn{1}{c}{ Affected organ: stomach, liver, lung, colon, bladder, larynx } \\
\hline Heart & $\begin{array}{l}\text { Atrial fibrillation, acute cardiac ischaemia, cardiac bypass surgery, angina pectoris, chronic heart } \\
\text { failure, dilated cardiomyopathy, sequelae of rheumatic fever }\end{array}$ \\
Lung & Pulmonary fibrosis, emphysema, chronic obstructive pulmonary disease, tracheostomy, asbestosis \\
Digestive organ & $\begin{array}{l}\text { Hepatic disorder, alcoholic liver disorder, liver cirrhosis, hepatic failure, alcoholic pancreatitis, peri- } \\
\text { tonitis, intestinal ileus, gastrostomy, gastrectomy }\end{array}$ \\
Kidney & Renal failure, nephrotic syndrome \\
Brain & Sequelae of cerebral infarction \\
Neurological disorder & Parkinson disease \\
Systemic & Anaemia, chronic thyroiditis, disuse syndrome \\
\hline
\end{tabular}

\section{Fig. 1. Flowchart of PTB case selection for analysis}

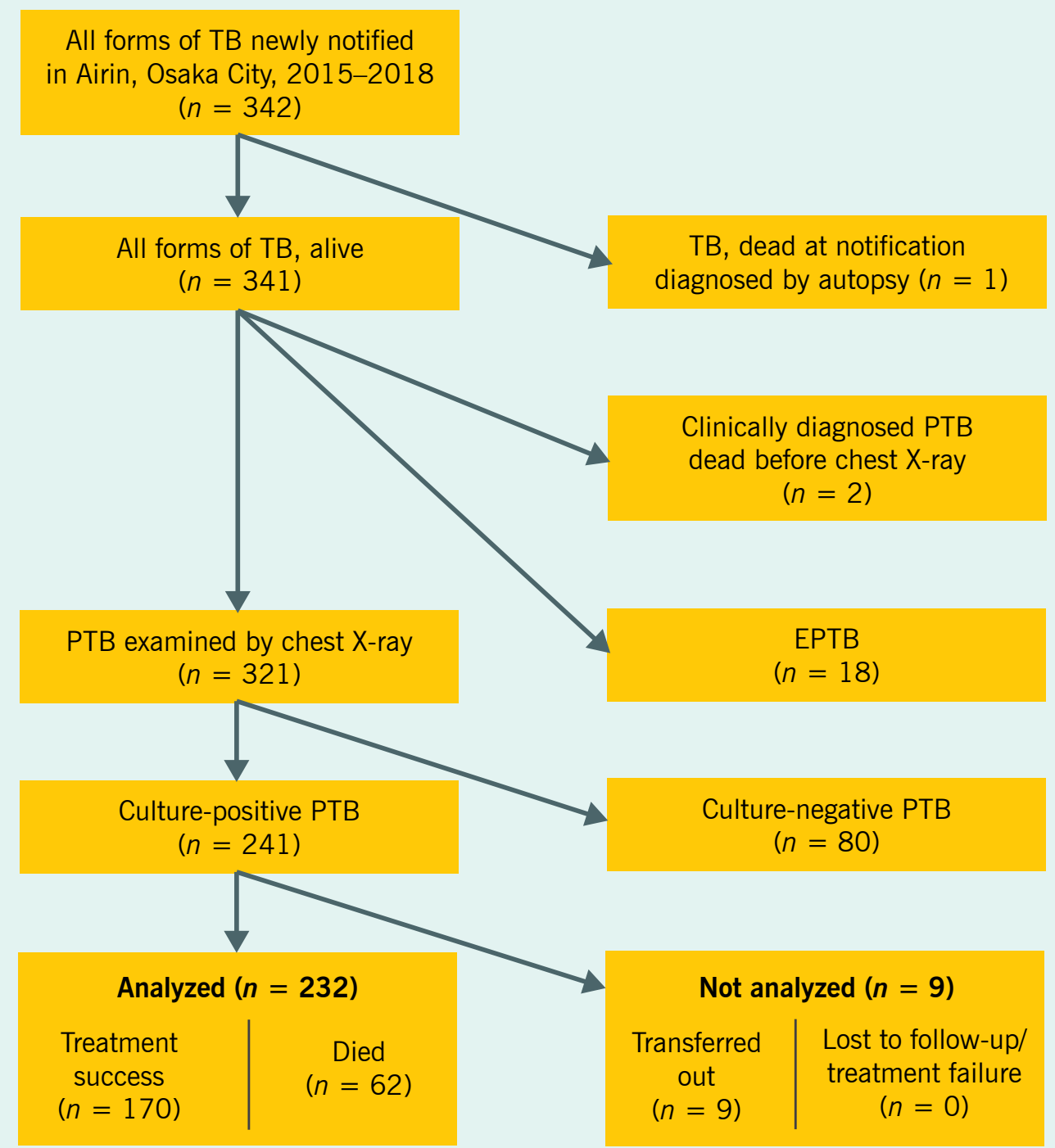

TB: tuberculosis; PTB: pulmonary tuberculosis; EPTB: extrapulmonary tuberculosis. 
Table 2. Univariate and multivariate analyses of characteristics associated with all deaths, early deaths and late deaths in pulmonary tuberculosis patients in Airin, Osaka City, 2015-2018

\begin{tabular}{|c|c|c|c|c|c|c|c|c|c|c|c|c|c|}
\hline \multirow[b]{2}{*}{ Characteristic } & \multirow[b]{2}{*}{$\begin{array}{c}\text { Treatment } \\
\text { success } \\
(n=170) \\
n(\%)\end{array}$} & \multicolumn{4}{|c|}{ All deaths $(n=62)$} & \multicolumn{4}{|c|}{ Early deaths $(n=29)$} & \multicolumn{4}{|c|}{ Late deaths $(n=33)$} \\
\hline & & $\begin{array}{c}n \\
(\%)\end{array}$ & $\begin{array}{c}\text { Univariate } \\
\text { analysis } \\
P\end{array}$ & $\begin{array}{c}\text { Multivariate } \\
\text { analysis } \\
\text { aOR } \\
(95 \% \mathrm{Cl})\end{array}$ & $P$ & $\begin{array}{c}n \\
(\%)\end{array}$ & $\begin{array}{c}\text { Univariate } \\
\text { analysis } \\
P\end{array}$ & $\begin{array}{c}\text { Multivariate } \\
\text { analysis } \\
\text { aOR } \\
(95 \% \mathrm{Cl})\end{array}$ & $P$ & $\begin{array}{c}n \\
(\%)\end{array}$ & $\begin{array}{c}\text { Univariate } \\
\text { analysis } \\
P\end{array}$ & $\begin{array}{c}\text { Multivariate } \\
\text { analyis } \\
\text { aOR } \\
(95 \% \mathrm{Cl})\end{array}$ & $P$ \\
\hline \multicolumn{14}{|l|}{ Sex } \\
\hline Male & $165(97.1)$ & $\begin{array}{c}57 \\
(91.9)\end{array}$ & 0.089 & $\begin{array}{c}0.19 \\
(0.02-1.55)\end{array}$ & 0.122 & $\begin{array}{c}28 \\
(96.6)\end{array}$ & 0.883 & & & $\begin{array}{c}29 \\
(87.9)\end{array}$ & 0.019 & $\begin{array}{c}0.11 \\
(0.01-1.01)\end{array}$ & 0.051 \\
\hline Female & $5(2.9)$ & $5(8.1)$ & & & & $1(3.4)$ & & & & $\begin{array}{c}4 \\
(12.1)\end{array}$ & & & \\
\hline \multicolumn{14}{|l|}{ Age } \\
\hline$\geq 70$ & $53(31.2)$ & $\begin{array}{c}37 \\
(59.7)\end{array}$ & $<0.001$ & $\begin{array}{c}2.66 \\
(1.11-6.35)\end{array}$ & 0.027 & $\begin{array}{c}19 \\
(65.5)\end{array}$ & $<0.001$ & $\begin{array}{c}4.39 \\
(1.32-14.63)\end{array}$ & 0.016 & $\begin{array}{c}18 \\
(54.5)\end{array}$ & 0.010 & $\begin{array}{c}2.01 \\
(0.73-5.54)\end{array}$ & 0.176 \\
\hline$<70$ & $117(68.8)$ & $\begin{array}{c}25 \\
(40.3)\end{array}$ & & & & $\begin{array}{c}10 \\
(34.5)\end{array}$ & & & & $\begin{array}{c}15 \\
(45.5)\end{array}$ & & & \\
\hline \multicolumn{14}{|l|}{ Country of birth } \\
\hline Japan & $168(98.8)$ & $\begin{array}{c}62 \\
(100)\end{array}$ & 0.391 & & & $\begin{array}{c}29 \\
(100)\end{array}$ & 0.557 & & & $\begin{array}{c}33 \\
(100)\end{array}$ & 0.532 & & \\
\hline Other & $2(1.2)$ & 0 & & & & $0(0)$ & & & & $0(0)$ & & & \\
\hline \multicolumn{14}{|l|}{ Homeless } \\
\hline Yes & $54(31.8)$ & $\begin{array}{c}14 \\
(22.6)\end{array}$ & 0.174 & & & $\begin{array}{c}6 \\
(20.7)\end{array}$ & 0.230 & & & $\begin{array}{c}8 \\
(24.2)\end{array}$ & 0.402 & & \\
\hline No & $116(68.2)$ & $\begin{array}{c}48 \\
(77.4)\end{array}$ & & & & $\begin{array}{c}23 \\
(79.3)\end{array}$ & & & & $\begin{array}{c}25 \\
(75.8)\end{array}$ & & & \\
\hline \multicolumn{14}{|c|}{ Cavity on chest X-ray } \\
\hline Yes & $55(32.4)$ & $\begin{array}{c}29 \\
(46.8)\end{array}$ & 0.043 & $\begin{array}{c}1.97 \\
(0.81-4.80)\end{array}$ & 0.134 & $\begin{array}{c}15 \\
(51.7)\end{array}$ & 0.043 & $\begin{array}{c}3.06 \\
(0.90-10.46)\end{array}$ & 0.073 & $\begin{array}{c}14 \\
(42.4)\end{array}$ & 0.254 & & \\
\hline No & $115(67.6)$ & $\begin{array}{c}33 \\
(53.2)\end{array}$ & & & & $\begin{array}{c}14 \\
(48.3)\end{array}$ & & & & $\begin{array}{c}19 \\
(57.6)\end{array}$ & & & \\
\hline \multicolumn{14}{|l|}{ Sputum smear } \\
\hline Positive & 107 (62.9) & $\begin{array}{c}55 \\
(88.7)\end{array}$ & $<0.001$ & $\begin{array}{c}5.03 \\
(1.51-16.80)\end{array}$ & 0.008 & $\begin{array}{c}25 \\
(86.2)\end{array}$ & 0.014 & $\begin{array}{c}3.82 \\
(0.79-18.32)\end{array}$ & 0.094 & $\begin{array}{c}30 \\
(90.9)\end{array}$ & 0.002 & $\begin{array}{c}7.79 \\
(1.53-39.76)\end{array}$ & 0.013 \\
\hline Negative & $63(37.1)$ & $\begin{array}{c}7 \\
(11.3)\end{array}$ & & & & $\begin{array}{c}4 \\
(13.7)\end{array}$ & & & & $3(9.1)$ & & & \\
\hline \multicolumn{14}{|c|}{ Susceptibility to isoniazid, rifampicin, ethambutol, streptomycin and pyrazinamide } \\
\hline Yes & $150(88.2)$ & $\begin{array}{c}55 \\
(88.7)\end{array}$ & 0.921 & & & $\begin{array}{c}25 \\
(86.2)\end{array}$ & 0.757 & & & $\begin{array}{c}30 \\
(90.9)\end{array}$ & 0.657 & & \\
\hline No & $20(11.8)$ & $\begin{array}{c}7 \\
(11.3)\end{array}$ & & & & $\begin{array}{c}4 \\
(13.8)\end{array}$ & & & & $3(9.1)$ & & & \\
\hline \multicolumn{14}{|c|}{ Body mass index $\left(\mathrm{kg} / \mathrm{m}^{2}\right)$} \\
\hline$<18.5$ & $49(29.5)$ & $\begin{array}{c}31 \\
(59.6)\end{array}$ & $<0.001$ & $\begin{array}{c}2.77 \\
(1.17-6.53)\end{array}$ & 0.020 & $\begin{array}{c}14 \\
(63.6)\end{array}$ & 0.001 & $\begin{array}{c}3.33 \\
(1.03-10.72)\end{array}$ & 0.044 & $\begin{array}{c}17 \\
(56.7)\end{array}$ & 0.004 & $\begin{array}{c}2.66 \\
(0.98-7.25)\end{array}$ & 0.056 \\
\hline$\geq 18.5$ & $117(70.5)$ & $\begin{array}{c}21 \\
(40.4)\end{array}$ & & & & $\begin{array}{c}8 \\
(36.4)\end{array}$ & & & & $\begin{array}{c}13 \\
(43.3)\end{array}$ & & & \\
\hline Unknown & 4 & 10 & & & & 7 & & & & 3 & & & \\
\hline \multicolumn{14}{|c|}{ Diabetes mellitus } \\
\hline Yes & $37(21.8)$ & $\begin{array}{c}12 \\
(20.3)\end{array}$ & 0.818 & & & $\begin{array}{c}5 \\
(18.5)\end{array}$ & 0.702 & & & $\begin{array}{c}7 \\
(21.9)\end{array}$ & 0.989 & & \\
\hline No & $133(78.2)$ & $\begin{array}{c}47 \\
(79.7)\end{array}$ & & & & $\begin{array}{c}22 \\
(81.5)\end{array}$ & & & & $\begin{array}{c}25 \\
(78.1)\end{array}$ & & & \\
\hline Unknown & & 3 & & & & 2 & & & & 1 & & & \\
\hline \multicolumn{14}{|c|}{ Other serious comorbidity } \\
\hline Yes & $41(24.1)$ & $\begin{array}{c}38 \\
(61.3)\end{array}$ & $<0.001$ & $\begin{array}{c}5.56 \\
(2.24- \\
13.81)\end{array}$ & $<0.001$ & $\begin{array}{c}18 \\
(62.1)\end{array}$ & $<0.001$ & $\begin{array}{c}6.15 \\
(1.79-21.13)\end{array}$ & 0.004 & $\begin{array}{c}20 \\
(60.6)\end{array}$ & $<0.001$ & $\begin{array}{c}6.45 \\
(2.35-17.69)\end{array}$ & $<0.001$ \\
\hline No & $129(75.9)$ & $\begin{array}{c}24 \\
(38.7)\end{array}$ & & & & $\begin{array}{c}11 \\
(37.9)\end{array}$ & & & & $\begin{array}{c}13 \\
(39.4)\end{array}$ & & & \\
\hline \multicolumn{14}{|c|}{ Detected by screening, including at outpatient department for other diseases } \\
\hline Yes & $94(55.3)$ & $3(4.8)$ & $<0.001$ & $\begin{array}{c}0.06 \\
(0.02-0.24)\end{array}$ & $<0.001$ & $1(3.4)$ & $<0.001$ & $\begin{array}{c}0.06 \\
(0.01-0.49)\end{array}$ & 0.009 & $2(6.1)$ & $<0.001$ & $\begin{array}{c}0.06 \\
(0.01-0.32)\end{array}$ & $<0.001$ \\
\hline No & $76(44.7)$ & $\begin{array}{c}59 \\
(95.2)\end{array}$ & & & & $\begin{array}{c}28 \\
(96.6)\end{array}$ & & & & $\begin{array}{c}31 \\
(93.9)\end{array}$ & & & \\
\hline
\end{tabular}


Table 3. Univariate and multivariate analyses of characteristics of TB-specific $(\boldsymbol{n}=35)$ and non-TB-specific deaths ( $n=27$ ) among pulmonary TB patients, Airin, Osaka City, 2015-2018

\begin{tabular}{|c|c|c|c|c|c|}
\hline Characteristic & $\begin{array}{c}\text { TB-specific deaths } \\
n(\%)\end{array}$ & $\begin{array}{c}\text { Non-TB-specific } \\
\text { deaths } n(\%)\end{array}$ & $\begin{array}{l}\text { Univariate } \\
\text { analysis } P\end{array}$ & $\begin{array}{l}\text { Multivariate analysis } \\
\text { aOR }(95 \% \mathrm{Cl})\end{array}$ & $P$ \\
\hline \multicolumn{6}{|l|}{ Sex } \\
\hline Male & $35(100 \%)$ & $23(85 \%)$ & 0.019 & & \\
\hline Female & $0(0 \%)$ & $4(15 \%)$ & & & \\
\hline \multicolumn{6}{|l|}{ Age (years) } \\
\hline$\geq 70$ & $21(60 \%)$ & $16(59 \%)$ & 0.953 & & \\
\hline$<70$ & $14(40 \%)$ & $11(41 \%)$ & & & \\
\hline \multicolumn{6}{|l|}{ Homeless } \\
\hline Yes & $9(26 \%)$ & $5(19 \%)$ & 0.502 & & \\
\hline No & $26(74 \%)$ & $22(81 \%)$ & & & \\
\hline \multicolumn{6}{|c|}{ Cavity on chest X-ray } \\
\hline Present & $20(57 \%)$ & $9(33 \%)$ & 0.062 & $2.26(0.73-6.94)$ & 0.155 \\
\hline Absent & $15(43 \%)$ & $18(67 \%)$ & & & \\
\hline \multicolumn{6}{|l|}{ Sputum smear } \\
\hline Positive & 33 (94\%) & $22(81 \%)$ & 0.114 & & \\
\hline Negative & $2(6 \%)$ & $5(19 \%)$ & & & \\
\hline \multicolumn{6}{|c|}{ Susceptible to isoniazid, rifampicin, ethambutol, streptomycin and pyrazinamide } \\
\hline Yes & $31(89 \%)$ & $24(89 \%)$ & 0.969 & & \\
\hline No & $4(11 \%)$ & $3(11 \%)$ & & & \\
\hline \multicolumn{6}{|l|}{ Body mass index } \\
\hline$<18.5$ & $16(59 \%)$ & $15(60 \%)$ & 0.957 & & \\
\hline$\geq 18.5$ & $11(41 \%)$ & $10(40 \%)$ & & & \\
\hline Unknown & 8 & 2 & & & \\
\hline \multicolumn{6}{|l|}{ Diabetes mellitus } \\
\hline Yes & $5(15 \%)$ & $7(27 \%)$ & 0.265 & & \\
\hline No & $28(85 \%)$ & $19(73 \%)$ & & & \\
\hline Unknown & 2 & 1 & & & \\
\hline \multicolumn{6}{|c|}{ Other serious comorbidity } \\
\hline Yes & $18(51 \%)$ & $20(74 \%)$ & 0.070 & $0.32(0.10-1.03)$ & 0.057 \\
\hline No & $17(49 \%)$ & $7(26 \%)$ & & & \\
\hline \multicolumn{6}{|c|}{ Detected by screening, including at outpatient department for other diseases } \\
\hline Yes & $2(6 \%)$ & $1(4 \%)$ & 0.715 & & \\
\hline No & $33(94 \%)$ & $26(96 \%)$ & & & \\
\hline \multicolumn{6}{|l|}{ Early death } \\
\hline Yes & $21(60 \%)$ & $8(30 \%)$ & 0.017 & $3.95(1.29-12.07)$ & 0.016 \\
\hline No & $14(40 \%)$ & $19(70 \%)$ & & & \\
\hline
\end{tabular}

The conditions included those listed in the Charlson comorbidity index and the Elixhauser comorbidity score as well as alcoholic pancreatitis, peritonitis, intestinal ileus and Parkinson disease (Table 1).

Treatment was completed by 170 patients, and
62 patients died before or during TB treatment, for a case fatality rate of $26.7 \%$. There were 29 (46.7\%) early deaths, including $3(4.8 \%)$ before treatment, and $33(53.2 \%)$ late deaths. Of the 59 patients who died during treatment, 55 (93.2\%) were hospitalized from the beginning of treatment until death. Two were discharged 
from hospital but were readmitted when their general condition deteriorated just before death. Five died in the community.

The binomial multivariate analysis showed that, in comparison with treatment success, death of PTB patients was significantly associated with age $\geq 70$ years, sputum smear positivity, underweight (BMI <18.5) and presence of serious comorbidity. Detection of TB at screening was inversely associated with mortality. All these variables, apart from sputum smear positivity, were also significantly associated with early death in PTB patients. In the comparison of treatment success and late deaths of PTB patients, positive sputum smear and serious comorbidity were significantly associated with late death, and detection by TB screening was inversely associated with late death (Table 2).

Of the 62 deaths, 35 were TB-specific and 27 non-TB-specific. Of the TB-specific deaths, $60.0 \%$ (21/35) were early deaths. In the multivariate analysis of patient characteristics for TB-specific and non-TBspecific deaths, TB-specific deaths were associated only with early death (aOR: 3.95, 95\% confidence interval: 1.29; 12.07) (Table 3).

\section{DISCUSSION}

The all-cause case fatality rate among culture-positive PTB patients in Airin, Osaka City, between 2015 and 2018 was $26.7 \%$. Multivariate analysis showed that age $\geq 70$ years, a positive sputum smear, BMI $<18.5$ and serious comorbidity were associated with mortality in PTB patients. Detection by active screening or during an OPD visit for another disease was inversely associated with mortality in PTB patients. The frequency of characteristics did not differ between TB-specific and non-TB-specific deaths. Similar results were reported in a much larger national study in the USA, although different methods were used to determine TB-specific deaths. ${ }^{10}$

Of the fatal PTB cases in Airin, $93 \%$ were in a hospital from the beginning of treatment until death. Almost all (92\%) of the cases during the study period received daily DOT in the Airin TB programme. None of the TB patients in the study failed treatment or were lost to follow-up; therefore, none of the deaths was due to treatment interruption or non-adherence, which may have contributed to deaths in other studies. ${ }^{8}$
About half of the fatalities among PTB patients were early deaths, occurring before or within the first 2 months of treatment. Similar findings were reported in Australia, ${ }^{6}$ Denmark, ${ }^{12}$ Taiwan (China), ${ }^{16}$ Spain, ${ }^{17}$ the Republic of Korea, ${ }^{18}$ the United Kingdom ${ }^{19}$ and Finland. ${ }^{20}$ We also found that a higher proportion of early deaths were TBspecific rather than non-TB-specific, which suggests that patients who survive $>2$ months of TB treatment have better outcomes, and late deaths are due more commonly to causes other than TB.

Advanced age is well recognized as a risk factor for morbidity and mortality from TB because of weakening of both the innate and adaptive immune systems. ${ }^{21}$ The presence of comorbidity has also been identified as the most common characteristic of death from TB in other developed countries, such as Australia, ${ }^{6}$ Denmark, ${ }^{12}$ Finland, ${ }^{20}$ the Netherlands, ${ }^{22}$ Spain, ${ }^{17}$ Singapore, ${ }^{23}$ the Republic of Korea, ${ }^{18}$ Taiwan (China) ${ }^{9,11,24}$ and the USA. ${ }^{10}$ Older people tend to be more vulnerable to comorbidity, as suggested by a one-day survey of the prevalence of morbidity in 2017 conducted by random stratified sampling in 6402 hospitals (76\% of hospitals in Japan), which showed that the rate of comorbidity among people aged $\geq 65$ years was 17 times higher than among those aged 20-24 years. ${ }^{25}$ In our study, both older age and having a comorbidity were associated with PTB mortality.

A BMI of $<18.5$ was significantly associated with all deaths and with early deaths of PTB patients in this study but not with late deaths of PTB patients. A similar finding was made in a study in Taiwan (China). ${ }^{16}$ Undernutrition impairs cell-mediated immunity, which increases vulnerability to specific infectious diseases, including TB. ${ }^{26,27}$ A BMI of $<18.5$ defines underweight and is a good proxy indicator of undernutrition. A literature review of cohort studies in the USA, Europe, India, Bangladesh and East Asia showed that being underweight was associated with a significantly higher risk for all-cause mortality. ${ }^{28}$

In contrast, our study showed that having a positive sputum smear status was associated with all deaths and late deaths in PTB patients but not with early deaths in these patients. A review of individual patient records in our study showed that about half of smear-negative cases had treatment delays of about 2 months until the culture became positive; however, the other half of smear-negative cases had no delay in TB treatment, because other methods of sputum smear examination on 
the same day led to a diagnosis of TB, e.g. cases in which TB bacilli were confirmed by nucleic acid amplification or chest X-ray showed typical infiltration of TB. This may explain our findings.

Detection of TB by screening and during an OPD visit for other diseases were both considered early diagnoses because these patients were unlikely to have symptoms of TB. In each of our analyses, early diagnosis was inversely associated with mortality from PTB, in that fatal PTB cases had significantly smaller odds of being detected with these early diagnosis measures. A study in Norway showed that the case fatality rate of TB patients detected through passive case finding due to symptoms was $11.1 \%$ and that of immigrants, close contacts of infectious cases and others screened for TB was $6.2 \%$, suggesting that patients who are symptomatic at diagnosis have a higher case fatality rate. ${ }^{29}$ In Airin, high-risk patients have the opportunity to undergo TB screening, as medical services are available to all through universal health coverage via health insurance or PAP.

The limitations to this study were as follows. Smoking, alcohol use and initial TB symptoms were excluded from the analysis because of lack of data, as the critical condition of patients who died early obviated questioning by PHNs during interviews. Therefore, delayed TB diagnosis was not included in the analysis. HIV infection was not included because TB/HIV co-infection was diagnosed for only $0.4 \%(42 / 10$ 038) of TB patients in Osaka City in 2008-2016 (unpublished data). The severity of comorbidities was determined from reported diagnoses, with no detailed clinical or laboratory test results. Finally, as a special chest X-ray screening programme is available only in Airin, as mentioned above, this study may not be generalizable to other parts of Osaka City.

\section{CONCLUSION}

Old age, severe disease, undernutrition and serious comorbidities were associated with mortality of PTB patients. Detection of PTB by chest X-ray screening and regular visits to OPDs for other diseases was associated with non-fatal TB, perhaps because they contributed to early case finding. Therefore, current active TB case finding and health education on regular visits to physicians for any disease should be further strengthened in the urban poor setting in Osaka City, Japan. Attending physicians should be advised to take periodic chest $X$-rays for aged patients with serious comorbidities or low $\mathrm{BMI}$, regardless of symptoms and even in other parts of Osaka City if the facilities are available.

\section{Acknowledgement}

The authors are grateful to the public health nurses of Nishinari District Public Health Offices for their hard work and data collection.

\section{Funding}

This research was partly supported by the Research Programme on Emerging and Re-emerging Infectious Diseases of the Japan Agency for Medical Research and Development, AMED (reference number: 19fk0108063s0202).

\section{Conflict of interest}

None declared.

\section{References}

1. The End TB Strategy. Geneva: World Health Organization; 2015. Available from: https://www.who.int/teams/global-tuberculosis-programme/the-end-tb-strategy, accessed 12 July 2021.

2. Tuberculosis control in Nishinari District: Report of special TB project in Nishinari District (in Japanese). Osaka: Nishinari Public Health Office; 2020. Available from: https://www.osaka-pha.or.jp/ suisin_02/pdf/shimoutiakira.pdf, accessed 12 July 2021.

3. Statistics of TB. 2019. Tokyo: Japan Anti-Tuberculosis Association; 2019. Available from: https://www.jata.or.jp/rit/ekigaku/en/statistics-of-tb/, accessed 12 July 2021.

4. Mizuuchi T, Hirakawa T, Tominaga T, editors. Fifty years' history of the Osaka Prefecture Urban Hostels' Association: Global Center of Excellence Report Series 17. Osaka: Osaka City University; 2011. (in Japanese). Available from: https://www.ur-plaza.osaka-cu.ac.jp/ wp1/wp-content/uploads/2016/06/GCOE_Report17.pdf, assessed 12 July 2021.

5. 2015 population census. Osaka City: Statistics Bureau, Ministry of Internal Affairs and Communications, Japan; 2021. Available from: https://www.e-stat.go.jp/en/stat-search, accessed 12 July 2021.

6. Walpola HC, Siskind V, Patel AM, Konstantinos A, Derhy P. Tuberculosis-related deaths in Queensland, Australia, 1989-1998: characteristics and risk factors. Int J Tuberc Lung Dis. 2003 Aug;7(8):742-50. pmid:12921150

7. Shuldiner J, Leventhal A, Chemtob D, Mor Z. Mortality of tuberculosis patients during treatment in Israel, 2000-2010. Int J Tuberc Lung Dis. 2014 Jul;18(7):818-23. doi:10.5588/ijtld.13.0591 pmid:24902558 
8. Nahid P, Jarlsberg LG, Rudoy I, de Jong BC, Unger A, Kawamura LM, et al. Factors associated with mortality in patients with drugsusceptible pulmonary tuberculosis. BMC Infect Dis. 2011 Jan 3;11(1):1. doi:10.1186/1471-2334-11-1 pmid:21199579

9. Yen YF, Chuang PH, Yen MY, Lin SY, Chuang P, Yuan MJ, et al. Association of body mass index with tuberculosis mortality, a population-based follow-up study. Medicine (Baltimore). 2016 Jan;95(1):e2300. doi:10.1097/MD.0000000000002300 pmid:26735532

10. Hannah HA, Miramontes R, Gandhi NR. Sociodemographic and clinical risk factors associated with tuberculosis mortality in the United States, 2009-2013. Public Health Rep. 2017 May/Jun;132(3):366-75. doi:10.1177/0033354917698117 pmid:28394707

11. Wu YC, Lo HY, Yang SL, Chu DC, Chou P. Comparing the factors correlated with tuberculosis-specific and non-tuberculosis-specific deaths in different age groups among tuberculosis-related deaths in Taiwan. PLoS One. 2015 Mar 3;10(3):e0118929. doi:10.1371/ journal.pone.0118929 pmid:25734444

12. Holden IK, Lillebaek $\mathrm{T}$, Andersen $\mathrm{PH}$, Wejse $\mathrm{C}$, Johansen IS Characteristics and predictors for tuberculosis related mortality in Denmark from 2009 through 2014: A retrospective cohort study. PLoS One. 2020 Jun 4;15(6):e0231821. doi:10.1371/journal. pone.0231821 pmid:32497102

13. Sundararajan V, Henderson T, Perry C, Muggivan A, Quan $H$, Ghali WA. New ICD-10 version of the Charlson comorbidity index predicted in-hospital mortality. J Clin Epidemiol. 2004 Dec;57(12):1288-94. doi:10.1016/j.jclinepi.2004.03.012 pmid:15617955

14. Li B, Evans D, Faris P, Dean S, Quan H. Risk adjustment performance of Charlson and Elixhauser comorbidities in ICD-9 and ICD10 administrative databases. BMC Health Serv Res. 2008 Jan 14;8(1):12. doi:10.1186/1472-6963-8-12 pmid:18194561

15. Shimouchi A, Tsuda $Y$, Komukai J, Matsumoto K, Yoshida $H$, Ohkado A. Characteristics of individuals with tuberculosis in an urban, poor population in Osaka City, Japan - a case-control study. 2020;11(1):22-8. doi:10.5365/wpsar.2018.9.1.005. pmid:32963888

16. Lai HH, Lai YJ, Yen YF. Y YF. Association of body mass index with timing of death during tuberculosis treatment. PLoS One. 2017 Jan 13;12(1):e0170104. doi:10.1371/journal.pone.0170104 pmid:28085951

17. Rodrigo T, Casals M, Caminero JA, García-García JM, JiménezFuentes MA, Medina JF, Millet JP, Ruiz-Manzano J, Caylá J, Working Group of the Integrated Programme of Tuberculosis Research. Factors associated with fatality during the intensive phase of antituberculosis treatment. PloS one. 2016 Aug 3;11(8):e0159925. doi:10.1371/journal.pone.0159925 pmid:27487189
18. Min J, Kim JS, Kim HW, Shin AY, Koo HK, Lee SS, et al. Clinical profiles of early and tuberculosis-related mortality in South Korea between 2015 and 2017: a cross-sectional study. BMC Infect Dis. 2019 Aug 22;19(1):735. doi:10.1186/s12879-019-4365-9 pmid:31438876

19. Pedrazzoli D, Kranzer K, Thomas HL, Lalor MK. Trends and risk factors for death and excess all-cause mortality among notified tuberculosis patients in the UK: an analysis of surveillance data. ERJ Open Res. 2019 Dec 16;5(4):00125. doi:10.1183/23120541.00125-2019 pmid:31857993

20. Korhonen V, Lyytikäinen O, Ollgren J, Soini H, Vasankari T, Ruutu P. Risk factors affecting treatment outcomes for pulmonary tuberculosis in Finland 2007-2014: a national cohort study. BMC Public Health. 2020 Aug 17;20(1):1250. doi:10.1186/s12889020-09360-7 pmid:32807112

21. Byng-Maddick R, Noursadeghi M. Does tuberculosis threaten our ageing populations? BMC Infect Dis. 2016 Mar 11;16(1):119. doi:10.1186/s12879-016-1451-0 pmid:26968654

22. Borgdorff MW, Veen J, Kalisvaart NA, Nagelkerke N. Mortality among tuberculosis patients in The Netherlands in the period 1993-1995. Eur Respir J. 1998 Apr;11(4):816-20. doi:10.1183/ 09031936.98.11040816 pmid:9623682

23. Low S, Ang LW, Cutter J, James L, Chee CBE, Wang YT, et al. Mortality among tuberculosis patients on treatment in Singapore. Int J Tuberc Lung Dis. 2009 Mar;13(3):328-34. pmid:19275792

24. Yen YF, Yen MY, Shih HC, Hu BS, Ho BL, Li LH, et al. Prognostic factors associated with mortality before and during anti-tuberculosis treatment. Int J Tuberc Lung Dis. 2013 Oct;17(10):1310-6. doi:10.5588/ijtld.12.0888 pmid:24025383

25. Outline of patient survey 2017. Tokyo: Ministry of Health, Labour and Welfare; 2017. Available from: https://www.mhlw.go.jp/toukei/list/10-20.html, accessed 12 July 2021.

26. Chandra RK. Nutritional deficiency and susceptibility to infection. Bull World Health Organ. 1979;57(2):167-77. pmid:108017

27. Chandra RK. Numerical and functional deficiency in $T$ helper cells in protein energy malnutrition. Clin Exp Immunol. 1983 Jan;51(1):126-32. pmid:6219837

28. Flegal KM, Kit BK, Graubard BI. Body mass index categories in observational studies of weight and risk of death. Am J Epidemiol. 2014 Aug 1;180(3):288-96. doi:10.1093/aje/kwu111 pmid:24893710

29. Farah MG, Tverdal A, Steen TW, Heldal E, Brantsaeter AB, Bjune G. Treatment outcome of new culture positive pulmonary tuberculosis in Norway. BMC Public Health. 2005 Feb 7;5(1):14 doi:10.1186/1471-2458-5-14 pmid:15698472 